\title{
3MR
}

\section{Isolation and characterization of novel polymorphic microsatellite loci in Perinereis aibuhitensis}

Y. Liu, D. Yu, Q. Wang, H. Liu, S. Guan and M. Liu

Marine Biology Institute of Shandong Province, Qingdao, Shandong, China

Corresponding author: M. Liu

E-mail: mliu@hsrl.rutgers.edu

Genet. Mol. Res. 15 (1): gmr.15017144

Received July 3, 2015

Accepted November 4, 2015

Published February 19, 2016

DOI http://dx.doi.org/10.4238/gmr.15017144

\begin{abstract}
Perinereis aibuhitensis is a commercially and ecologically important intertidal worm. In this study, eight polymorphic microsatellite loci were isolated in this species for the first time, and a wild population was used to estimate the properties of these loci. The number of alleles per locus ranged from 6 to 20 , and the observed and expected heterozygosities ranged from 0.375 to 0.875 and from 0.590 to 0.946 , respectively. These microsatellite loci will act as effective markers for related $P$. aibuhitensis studies, and the data will be helpful for the rational exploitation and conservation of this species.
\end{abstract}

Key words: Perinereis aibuhitensis; Microsatellite loci; Polymorphism 


\section{INTRODUCTION}

Perinereis aibuhitensis (Nereididae family) is a common clamworm that is distributed in the soft-bottom estuaries and intertidal zones of the northwestern Pacific (Sun and Yang, 2004). It has recently become a commercially important species, because it is widely used as feed in aquaculture due to its high nutrient content or as bait for recreational fisheries. Besides its commercial value, this species also has an important ecological role, because most worms improve the physical, chemical, and biological properties of sediments, thereby benefiting intertidal ecosystems. Artificial breeding and culture of $P$. aibuhitensis has recently been established in China; therefore, additional knowledge about its genetic background is required. However, studies on $P$. aibuhitensis are limited. Microsatellite loci have been demonstrated to be powerful genetic markers that have distinct advantages and extensive applications in population genetics, evolutionary biology, DNA profiling, linkage analysis, marker assisted selection, etc. (Li, 2006). In this study, we attempted to isolate polymorphic microsatellite loci in $P$. aibuhitensis, and these loci are expected to provide useful tools to elucidate the genetic background of this species and to facilitate sustainable resource exploitation and conservation.

\section{MATERIAL AND METHODS}

Microsatellite loci were isolated following the enrichment protocols of Glenn and Schable (2005). Genomic DNA of $P$. aibuhitensis was extracted using a Genomic DNAExtraction Kit (Tiangen, China). DNA was digested with BstUI and Rsal restriction enzymes (New England Biolabs, UK). SuperSNX-24 double-stranded adaptors (forward: 5'-GTTTAGGCCTAGCTAGCAGAATC-3', reverse: 5'-GATTCTGCTAGCTAGGCCTTAAACAAAA-3') were ligated to each end of the fragments using T4 DNA ligase (New England Biolabs). Subsequently, the ligation products were hybridized with a biotinylated dinucleotide repeat sequence $(\mathrm{TG})_{12}$. Fragments containing simple repeat sequences were then captured by streptavidin-coated magnetic beads (Dynabeads M-280, Invitrogen, USA), washed, and recovered by heating and ethanol precipitation. The enriched fragments were amplified via PCR using the SuperSNX-24 forward primer. The PCR products were ligated to the pMD19-T vector (Takara, Japan), and were then transformed into Trans1-T1 competent cells (TransGen, China).

A total of 237 positive clones were selected using blue/white screening, and were then sequenced using an ABI PRISM 3730XL DNA Analyzer. After analysis of these sequences, 65 clones containing at least twelve uninterrupted repeats were identified using the MISA software (http://pgrc.ipk-gatersleben.de/misa/). A total of 39 microsatellite primer pairs were designed using the Primer Premier 5.0 software (http://www.pre mierbiosoft.com/). The optimum primer annealing temperatures were determined using gradient temperature PCR. The amplified products were visualized on $1 \%$ agarose gels. Twenty pairs of primers that produced clear bands (approximately 100 to $500 \mathrm{bp}$ ) were qualified, and were then applied to 24 samples of wild $P$. aibuhitensis collected from Jiaonan, China. Tailed PCR was used to produce fluorescently labeled DNA fragments, and analyses were conducted following the protocol of Liu and Avise (2011). Genotyping was performed using an ABI PRISM 3730XL DNA Analyzer. Allele sizes were determined using the GeneMarker 2.2.0 software (SoftGenetics, State College, PA, USA).

The number of alleles per locus $\left(N_{A}\right)$, the polymorphic information content (PIC), and the observed $\left(H_{\mathrm{O}}\right)$ and expected $\left(H_{\mathrm{E}}\right)$ heterozygosity values were calculated using the PopGen32 
software (version 1.32; Yeh et al., 2000). Deviations from Hardy-Weinberg equilibrium (HWE) and genotypic linkage disequilibrium were tested using the Genepop 4.0 software (Rousset, 2008). The Micro-Checker software (version 2.2.0; van Oosterhout et al., 2004) was used to detect null alleles, stuttering, and large allele dropout.

\section{RESULTS AND DISCUSSION}

Our results indicated that eight of the 20 analyzed loci were polymorphic (Table 1). $N_{\mathrm{A}}$ values ranged from 6 to 20 , and PIC values ranged from 0.535 to $0.921 . H_{\mathrm{O}}$ and $H_{\mathrm{E}}$ values ranged from 0.375 to 0.875 and from 0.590 to 0.94 , respectively. No significant linkage disequilibrium was detected for any pairwise combination of loci. All of the loci were at HWE after sequential Bonferroni corrections, and no significant linkage disequilibrium was detected for any pairwise combination of loci. No evidence was found for null alleles, large allele dropout, or scoring error. These novel microsatellite loci will further contribute to genetic, evolutionary, and ecological studies of $P$. aibuhitensis, especially those associated with intraspecific genetic diversity, population structure, and kinship analysis. Moreover, these loci will facilitate rational exploitation and conservation of $P$. aibuhitensis.

\begin{tabular}{|c|c|c|c|c|c|c|c|c|}
\hline Locus & Repeat motif & Primer sequence $\left(5^{\prime}-3^{\prime}\right)$ & Size range (bp) & $\mathrm{Ta}\left({ }^{\circ} \mathrm{C}\right)$ & $H_{E}$ & PIC & $H_{0}$ & $N_{A}$ \\
\hline L39 & $(\mathrm{TC}) \mathrm{n}$ & $\begin{array}{l}\text { F: GCTGGGTTGTCTAGTGGT } \\
\text { R: AAAGGACGGTTCTGACTG }\end{array}$ & $249-287$ & 59 & 0.852 & 0.814 & 0.783 & 13 \\
\hline L48 & $(\mathrm{TC})_{12} \mathrm{TT}(\mathrm{TC})_{13}$ & $\begin{array}{l}\text { F: CTGAATAAGCCGAGACAT } \\
\text { R: AGAGTAGCCCACTAAGGT }\end{array}$ & $234-298$ & 48 & 0.901 & 0.868 & 0.619 & 12 \\
\hline L107 & (GT) & $\begin{array}{l}\text { F: AGGGGCTTGGAATGTTAT } \\
\text { R: TGAAGGGAGCCAGTATTT }\end{array}$ & $152-182$ & 53 & 0.946 & 0.921 & 0.875 & 18 \\
\hline L147 & $(\mathrm{TC})_{33} \mathrm{CC}(\mathrm{TC})_{12}$ & $\begin{array}{l}\text { F: TACCAATCAGGTGGCTCT } \\
\text { R: CCTATCCAGAACAGAAGC }\end{array}$ & $218-282$ & 57 & 0.945 & 0.919 & 0.818 & 20 \\
\hline L204 & $(\mathrm{CA})_{10}$ & $\begin{array}{l}\text { F: ACCCGCATTGAAAAGTGT } \\
\text { R: TCCCAGACTATGTCGTCG }\end{array}$ & $99-109$ & 58 & 0.590 & 0.535 & 0.375 & 6 \\
\hline L.210 & $(G A) 43$ & $\begin{array}{l}\text { F: CACGAAGCAAAGGTCAAT } \\
\text { R: TGTGTAGTGTAAGTGAACGG }\end{array}$ & $265-291$ & 48 & 0.789 & 0.736 & 0.619 & 7 \\
\hline L230 & $(A G)_{20}$ & $\begin{array}{l}\text { F: CTITTGAAGACTCTGGGT } \\
\text { R: GGTGATGTGACGGTTAG }\end{array}$ & $276-326$ & 48 & 0.914 & 0.886 & 0.792 & 16 \\
\hline L.235 & $(G A) 53$ & $\begin{array}{l}\text { F: TTCAAGCCTGGATAGTGG } \\
\text { R: GCAAAGAGTAAAGCCTACATCG }\end{array}$ & $237-297$ & 60 & 0.940 & 0.914 & 0.435 & 18 \\
\hline
\end{tabular}

Annealing temperature (Ta), number of alleles $\left(N_{\mathrm{A}}\right)$, observed heterozygosity $\left(H_{\mathrm{O}}\right)$, expected heterozygosity $\left(H_{\mathrm{E}}\right)$, and polymorph information content (PIC).

\section{Conflicts of interest}

The authors declare no conflict of interest.

\section{ACKNOWLEDGMENTS}

Research supported by the Science and Technology Project of Shandong Provincial Oceanic and Fishery Administrative Department, the Agricultural Technology Innovation Project of Shandong Province, and the National Marine Public Welfare Research Project (\#201005007). 


\section{REFERENCES}

Glenn TC and Schable NA (2005). Isolating microsatellite DNA loci. Methods Enzymol. 395: 202-222. http://dx.doi.org/10.1016/ S0076-6879(05)95013-1

Li Q (2006). Development of microsatellite DNA markers and their applications in genetic studies of marine mollusks. J. Fish. Sci. China 3: 503-509.

Liu JX and Avise JC (2011). High degree of multiple paternity in the viviparous Shiner Perch, Cymatogaster aggregata, a fish with long-term female sperm storage. Mar. Biol. 158: 893-901.http://dx.doi.org/10.1007/s00227-010-1616-0

Rousset $F$ (2008). genepop'007: a complete re-implementation of the genepop software for Windows and Linux. Mol. Ecol. Resour. 8: 103-106.http://dx.doi.org/10.1111/j.1471-8286.2007.01931.x

Sun R and Yang DJ (2004). Fauna sinica, Invertebrata. In: Annelida, Polychaeta (II), Nereidida, vol. 33. Science Press, Beijing, China.

Van Oosterhout C, Hutchinson WF, Wills DP and Shipley P (2004). MICRO-CHECKER: software for identifying and correcting genotyping errors in microsatellite data. Mol. Ecol. Notes 4: 535-538. http://dx.doi.org/10.1111/j.1471-8286.2004.00684.x

Yeh FC, Yang R, Boyle TJ and Ye Z (2000). PopGene32, Microsoft Windows-based freeware for population genetic analysis, version 1.32. Molecular Biology and Biotechnology Centre, University of Alberta, Alberta. 